\title{
Utilização do primeiro ciclo ovulatório da estação reprodutiva para produção de embriões em éguas sob condições tropicais
}

Karen Regina PERES ${ }^{1}$

Fernanda da Cruz LANDIM-

ALVARENGA ${ }^{2}$

Marco Antonio

ALVARENGA ${ }^{2}$

\section{Correspondência para:}

FERNANDA DA CRUZ LANDIMALVARENGA

Departamento de Reprodução Animal e Radiologia Veterinária

Faculdade de Medicina Veterinária e Zootecnia

Uiversidade Estadual Paulista

Distrito de Rubião Júnior, $\mathrm{s} / \mathrm{n}$

18618-000 - Botucatu - SP

krperes@ig.com.br

Recebido para publicação: 24/05/2004 Aprovado para publicação: 23/08/2005

\begin{abstract}
1 - Departamento de Reprodução Animal da Faculdade de Medicina Veterinária e Zootecnia da Universidade de São Paulo, São Paulo - SP 2 - Departamento de Reprodução Animal e Radiologia Veterinária da Faculdade de Medicina Veterinária e Zootecnia da Universidade Estadual Paulista, Botucatu - SP
\end{abstract}

\section{Resumo}

Palavras-chave:

A eficiência da primeira ovulação da estação reprodutiva para a produção de embriões foi determinada através da taxa de recuperação embrionária, da viabilidade dos embriões recuperados, da concentração sérica de progesterona, da resposta do primeiro folículo pré-ovulatório da estação reprodutiva ao hCG e da resposta do primeiro CL a PGF $\alpha$. Treze éguas que estavam no período de anestro ou inicial da transição de primavera foram acompanhadas por ultra-sonografia até a detecção do primeiro folículo pré-ovulatório. Neste momento a ovulação foi induzida com 2500 UI de hCG (IV) e elas foram inseminadas em dias alternados até a ovulação. Sete dias após a detecção da ovulação foi realizada coleta de embrião e a concentração de $\mathrm{P}_{4}$ foi determinada. A partir da detecção do primeiro folículo $\geq 25 \mathrm{~mm}$ da estação, as éguas demoraram em média 14,92 \pm 10,80 dias para alcançarem o primeiro folículo pré-ovulatório e 18,00 \pm 11,08 dias para ovularem, sendo que 11/13 éguas ovularam em até 48 horas após a administração do hCG. Estes folículos cresceram em média 2,19 $\pm 0,86 \mathrm{~mm} /$ dia. Nove das 13 éguas $(69,2 \%)$ produziram embriões e todos foram considerados viáveis após avaliação visual e pelo exame de fluorescência. Os corpos lúteos formados mostraram-se funcionalmente competentes produzindo em média $7,39 \pm 2,11 \mathrm{ng} / \mathrm{ml}$ de $\mathrm{P}_{4}$, além de serem responsivos à $\mathrm{PGF}_{2} \alpha$. Deste modo, o primeiro ciclo ovulatório do ano pode ser utilizado com sucesso para a produção de embriões viáveis.

\section{Introdução}

O uso da transferência de embriões em eqüinos tem aumentado nas últimas décadas, sendo o Brasil um dos paises que mais utiliza esta técnica em todo o mundo. Apesar do inegável benefício da aplicação da transferência de embriões para a eqüideocultura, a técnica ainda possui algumas limitações. Além do fato de ocorrer, via de regra, somente uma ovulação por ciclo, resultando na recuperação de no máximo um embrião por coleta, a estacionalidade reprodutiva da espécie limita ainda mais o número de embriões obtidos por ano.

Nas éguas, a atividade reprodutiva sofre influência positiva da luminosidade, o que as classifica como uma espécie poliéstrica estacional. Devido, principalmente, às alterações no fotoperíodo, a incidência de ovulações é mínima ou ausente durante o inverno, aumenta gradualmente durante a primavera, se normaliza durante o verão, e diminui transicionalmente durante o outono. Até a ocorrência da primeira ovulação da estação ovulatória, muitas ondas de crescimento folicular ocorrem estimuladas 
pelas ondas de $\mathrm{FSH}^{1}$, porém, apenas com o aumento dos níveis séricos de LH, concomitante à queda dos níveis de FSH, um folículo continua o seu crescimento e culmina em ovulação ${ }^{2,3}$. Sharp e Ginther ${ }^{4}$ descreveram o padrão de crescimento folicular de éguas durante a transição de primavera como uma curva sigmóide, ou seja, um crescimento, inicialmente lento, no número e tamanho dos folículos, que depois se acentua. Este aumento acentuado no número e tamanho dos folículos é seguido por um platô antes da data da primeira ovulação, sendo que, durante o período de rápido e extenso desenvolvimento folicular não ocorrem ovulações.

A sazonalidade reprodutiva de éguas nas condições do Brasil tem sido pouco estudada, e pouca atenção tem sido dada, na literatura, ao primeiro ciclo ovulatório do ano. Adicionalmente, não existem relatos sobre a utilização do primeiro ciclo ovulatório para a produção de embriões. Desta forma a obtenção de embriões viáveis já no primeiro ciclo ovulatório da estação viria a aumentar o desempenho de fêmeas em programas de transferência de embriões. Também pouco se tem estudado sobre a eficácia da utilização da gonadotrofina coriônica humana (hCG) em éguas na fase transicional ${ }^{5,6}$, que há muito tempo é utilizada para acelerar a ovulação em éguas que se encontram ciclando ${ }^{7,8}$, assim como, a função do corpo lúteo após a sua administração.

Com o objetivo de se determinar a real eficiência em se utilizar ou não o primeiro ciclo da estação reprodutiva, este trabalho visou estudar: a) o intervalo entre a fase final do período de transição de primavera e a primeira ovulação da estação ovulatória de éguas na região de Botucatu, São Paulo; b) a taxa de recuperação embrionária utilizando o primeiro folículo ovulatório; c) a viabilidade e morfologia destes embriões, observada in vitro; d) a função do corpo lúteo formado após a primeira ovulação do ano, através da determinação da concentração sérica de progesterona; e) a sensibilidade do primeiro folículo pré-ovulatório do ano ao
hCG e, f) verificar a resposta do primeiro corpo lúteo da estação reprodutiva à prostaglandina $\mathrm{F}_{2} \alpha\left(\mathrm{PGF}_{2} \alpha\right)$ através do intervalo entre a administração da $\operatorname{PGF}_{2} \alpha$ e a segunda ovulação da estação reprodutiva.

\section{Materiais e Métodos}

Foram utilizadas 13 éguas mestiças, de três a 15 anos, com bom escore corporal, peso compreendido entre 300 e $400 \mathrm{~kg}$ e bom histórico reprodutivo. As éguas foram mantidas sob sistema de criação extensiva em piquetes de pasto nativo da Fazenda Edgárdia, pertencente à Universidade Estadual Paulista (UNESP) - Campus de Botucatu (Latitude 2252'S; Longitude 48 $27^{\prime}$ S; Altitude aproximada de 825 metros), Estado de São Paulo. Os animais tinham acesso a bebedouro coletivo e a suplementação mineral, e recebiam diariamente $2 \mathrm{~kg}$ de ração peletizada para manutenção.

O trato reprodutivo das éguas foi examinado por palpação retal e por ultrasonografia, durante a primeira quinzena do mês de setembro de 2003, antes do início do experimento. Todos os animais encontravam-se na fase de anestro ou no início da fase de transição de primavera (folículos menores que $25 \mathrm{~mm}$ de diâmetro e nenhum corpo lúteo). Também não apresentavam qualquer alteração endometrial (avaliada através de biópsia uterina) e/ou cervical (avaliada através de vaginoscopia).

Os ovários e útero das éguas foram avaliados duas a três vezes por semana, com ultra-som Pie-Medical modelo 450 e transdutor linear de 5,0 MHz. Uma vez detectado o primeiro folículo com diâmetro médio de $25 \mathrm{~mm}$, o desenvolvimento folicular foi acompanhado com intervalo máximo de 72 horas até que fosse observado um folículo com diâmetro igual ou superior a $30 \mathrm{~mm}$, momento em que o acompanhamento folicular tornou-se diário. A partir da detecção de um folículo préovulatório $(\geq 35 \mathrm{~mm})$ e da observação de edema uterino, com presença de dobras 
endometriais bem visibilizadas ${ }^{7}$, as éguas receberam, via endovenosa, 2.500 UI de gonadotrofina coriônica humana (hCG) (Vetecor $^{\circledR}$ - Lab. Calier do Brasil Ltda, São Paulo) e foram inseminadas artificialmente, em dias alternados, até o momento da ovulação. Utilizou-se sêmen fresco, proveniente de um único garanhão de fertilidade comprovada, diluído na proporção de 1:1 em meio extensor a base de leite desnatado (K75), desenvolvido pelo Departamento de Reprodução Animal e de Radiologia Veterinária - FMVZ - UNESP, campus de Botucatu. A dose inseminante continha no mínimo 500 milhões de espermatozóides móveis. O dia da detecção da ovulação foi determinado como dia zero (D0) e a recuperação embrionária foi realizada no $7^{\circ}$ dia (D7) após a ovulação.

Utilizou-se a técnica não-cirúrgica para a recuperação embrionária, realizando-se três lavados uterinos com solução de Ringer com Lactato (J.P. Indústria Farmacêutica, Ribeirão Preto, São Paulo), conforme descrito por Alvarenga, Landim - Alvarenga e Meira? Após o procedimento, as éguas receberam 7,5 mg (1,5 ml) de Dinoprost Trometamina (Lutalyse $^{\circledR}$ - Rhodia-Mérieux Veterinária Ltda, São Paulo), via intramuscular.

O rastreamento dos embriões foi realizado com auxílio de um microscópio esteroscópico (lupa) sob aumento de 10 vezes, e a classificação embrionária utilizando-se aumento de 40 vezes, conforme McKinnon e Squires ${ }^{10}$. Visando avaliar a viabilidade embrionária através de sondas fluorescentes, seis embriões foram incubados em solução de DPBS com $0,4 \%$ de BSA acrescida de $125 \mathrm{mg} / \mathrm{ml}$ de iodeto de propídeo (Sigma Chemical CO, St. Louis) durante 10 minutos, e em seguida foram transferidos para uma gota, sobre lâmina histológica, contendo solução de $10 \mathrm{mg} / \mathrm{ml}$ de solução de trabalho de HOECHST 33342 (Sigma Chemical CO, St. Louis) e cobertos por lamínula. Os embriões então foram imediatamente examinados em microscópio invertido de fluorescência (filtro azul 535 e $617 \mathrm{~nm}$ ) para a determinação da sua viabilidade, sendo considerados viáveis células com núcleos corados em azul pelo HOECHST 33342 e inviáveis células com núcleo corado em vermelho pelo Iodeto de Propídeo.

Visando a análise ultra-estrutural, três embriões foram fixados em glutaraldeído a $2,5 \%$ em tampão fosfato $0,1 \mathrm{M}(\mathrm{pH} 7.4) \mathrm{e}$ pós-fixados em tetróxido de ósmio a 1\% em mesmo tampão. Após a desidratação em séries crescentes de acetona os embriões foram incluídos em Epon. Os cortes ultrafinos foram obtidos com navalha de diamante, montados em grades de cobre e corados com acetato de uranila e citrato de chumbo. As amostras foram então examinadas em microscópio eletrônico de transmissão Philips EM 301. A análise foi feita em um pequeno número de estruturas devido ao alto custo da técnica objetivando somente a descrição morfológica dos embriões colhidos.

No dia estabelecido para a coleta embrionária (D7), realizou-se coleta de sangue, através de punção venosa, com auxílio do sistema de "Vacutainer" sem anticoagulante. As amostras foram centrifugadas e o soro foi devidamente identificado e armazenado a $16^{\circ} \mathrm{C}$. A concentração de progesterona foi determinada por radioimunoensaio utilizandose kit comercial (Coat-A-Count - Diagnostic Products CO, Califórnia, EUA), e, foi realizada no Laboratório de Endocrinologia do Departamento de Reprodução Animal da UNESP-Botucatu.

Nos dias que sucederam o procedimento, as éguas continuaram a ser acompanhadas através de palpação retal e ultra-sonografia. No momento em que foi detectado o próximo folículo com características de folículo pré-ovulatório, os animais receberam novamente 2.500 UI de hCG para a indução da ovulação. A data da segunda ovulação também foi determinada.

\section{Análise Estatística}

O intervalo entre o final da fase de transição de primavera e o primeiro folículo pré-ovulatório e o intervalo entre o final da 
fase de transição de primavera e a primeira ovulação da estação ovulatória foram determinados pela média dos intervalos observados para cada égua, com seus respectivos desvios padrão.

Para o estudo da dinâmica dos folículos que culminaram em ovulação, durante o primeiro ciclo ovulatório da estação reprodutiva, foi realizada análise de regressão linear simples.

Utilizou-se uma análise descritiva para a avaliação da morfologia embrionária.

$\mathrm{O}$ intervalo entre a administração da $\mathrm{PGF}_{2} \alpha$ e a segunda ovulação da estação foi determinado pela média dos intervalos observados para cada égua, com seu respectivo desvio padrão.

\section{Resultados}

A partir da detecção do primeiro folículo com diâmetro $\geq 25 \mathrm{~mm}$, as éguas demoraram em média 14,92 \pm 10,80 dias (2-42 dias) para alcançarem o primeiro folículo pré-ovulatório e, 18,00 \pm 11,08 dias (6-47 dias) para ovularem. Onze das 13 éguas $(84,6 \%)$ ovularam entre 36 e 48 horas após a administração do hCG, enquanto duas ovularam após 96 e 120 horas. Todas desenvolveram apenas um folículo préovulatório e tiveram presumivelmente apenas uma ovulação.

Os folículos ovulatórios apresentaram uma taxa de crescimento média de 2,19 $\pm 0,86 \mathrm{~mm}$ por dia, obedecendo a um padrão de crescimento linear $(y=1,88 \mathrm{x}+$ 40,$\left.82 ; r^{2}=0,96\right)$ (Figura 1), sendo que, $\mathrm{x}=$ (-) número de dias que antecedem a ovulação e y $=$ diâmetro folicular em milímetros. Nove dias antes da ovulação os folículos apresentaram 25,4 \pm 2,2 $\mathrm{mm}$ de diâmetro, com oito dias antes da ovulação apresentaram $24 \pm 3,8 \mathrm{~mm}$, com sete dias antes da ovulação apresentaram 27,5 \pm 3,5 $\mathrm{mm}$, com seis dias antes da ovulação tinham $30,3 \pm 4,6 \mathrm{~mm}$, com cinco dias antes da ovulação apresentaram $31 \pm 3,6 \mathrm{~mm}$, quatro dias antes da ovulação tinham $32,8 \pm 4,1$ $\mathrm{mm}$, três dias antes tinham $35,4 \pm 2,7 \mathrm{~mm}$ e dois dias antes apresentaram 38,4 $\pm 3,4 \mathrm{~mm}$. Por fim, o diâmetro folicular médio apresentado no dia que antecedeu a ovulação foi igual a $38,1 \pm 4,4 \mathrm{~mm}$.

A taxa de recuperação embrionária foi igual a $69,2 \%(9 / 13)$.

Viabilidade embrionária "in vitro" dos nove embriões recuperados, oito $(88,9 \%)$ foram classificados como grau 1-1,5 e apenas um $(11,1 \%)$ como grau 2-2,5. Todos os embriões que foram corados e submetidos ao exame de fluorescência se mostraram viáveis, pois apresentaram no máximo 10 células coradas de vermelho (inviáveis) (Figura 2a e 2b).

\section{Análise ultra-estrutural}

Pela análise da ultra-estrutura os embriões apresentaram zona pelúcida de aproximadamente $4 \mathrm{~mm}$ de espessura se desfazendo em alguns pontos. A cápsula consistia de um envelope localizado entre a zona pelúcida e as células do trofoblasto formado por um material fibrilar arranjado circularmente sob a forma de camadas sobrepostas (Figura 3a). O espaço perivitelínico, compreendido entre a cápsula e as células do trofoblasto, era estreito e preenchido quase que totalmente pelas microvilosidades presentes na superfície externa das células (Figura 3b). As células do trofoblasto encontram-se unidas entre si por estruturas de adesão, em sua parte apical. Complexos juncionais, caracterizados pela presença de zônulas de oclusão apareceram fechando os espaços intercelulares apicais, ou seja, voltados para o espaço perivitelínico (Figura $3 \mathrm{~d}$ ). $\mathrm{Na}$ região do botão embrionário foi vista uma massa celular interna composta por células dispersas envoltas por um epitélio colunar formado por uma única camada de células, o trofoblasto (Figura 3a). A massa celular interna apresentou-se constituída por células de aspecto irregular, com núcleo oval localizado centralmente, contendo cromatina de aspecto difuso (Figura 3c). Os glóbulos de lipídeos apareceram em grande número, muitas vezes posicionados próximo a 
superfície celular (Figuras 3a e 3c). O citoplasma dessas células emitia longos prolongamentos ligando uma célula à outra, bem como com as células do trofoblasto (Figuras 3a e 3c). Não foi observado nenhum tipo especial de junção celular entre os prolongamentos sendo a ligação entre uma célula e outra feita somente pela aposição das duas membranas (Figura 3c).
Após o procedimento de coleta do embrião, as éguas receberam uma dose de luteolítico $\left(\mathrm{PGF}_{2} \alpha\right)$ e ovularam pela segunda vez após 10,92 \pm 3,50 dias em média (4 17 dias), sendo que esta segunda ovulação também foi induzida com hCG.

A concentração sérica de progesterona apresentada, no dia da coleta de embrião, foi igual a 7,39 $\pm 2,11 \mathrm{ng} / \mathrm{ml} \mathrm{em}$

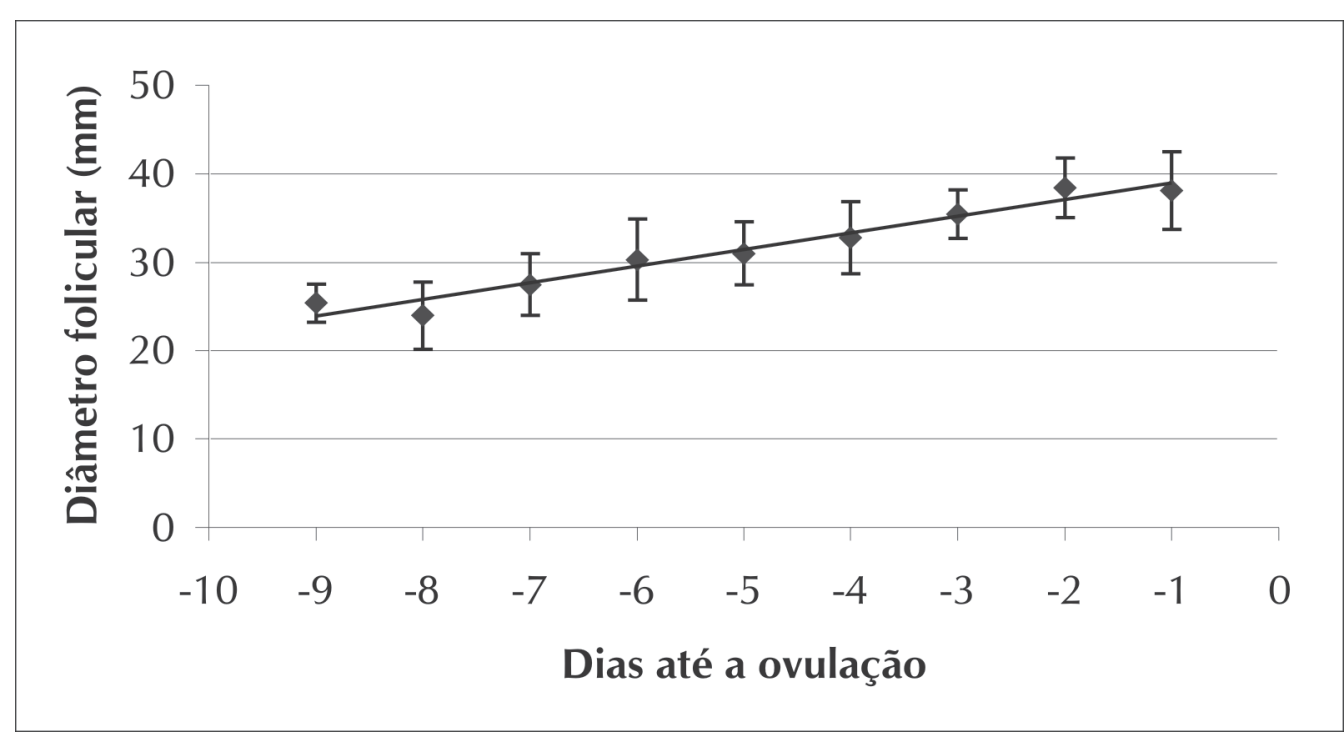

$y=1,88 x+40,82\left(r^{2}=0,96\right)$

Figura 1 - Crescimento folicular médio (mm) apresentado pelos primeiros folículos ovulatórios do ano. Botucatu,

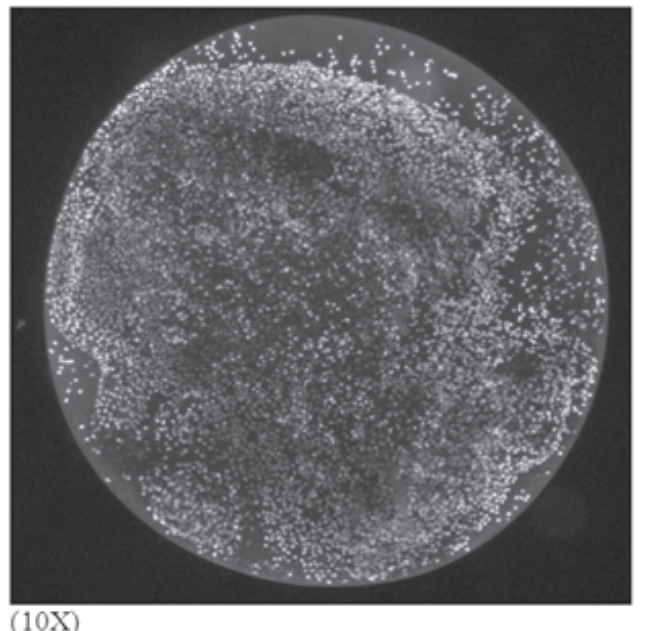

$(10 \mathrm{X})$

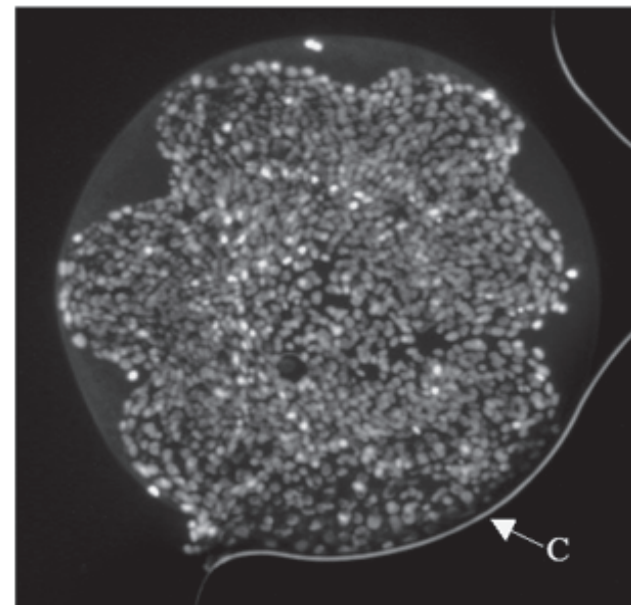

$(10 \mathrm{X})$

$\mathrm{C}=$ cápsula

Figura 2 - Embriões eqüinos (D7) corados com lodeto de Propídeo e HOECHST 33342, examinados em microscópio invertido de fluorescência (10x). Observe raras células (blastômeros) coradas de vermelho (inviáveis) 
média, sendo que os valores mínimo e máximo foram de 4,304 e 11,594 ng/ml.

\section{Discussão}

Este estudo demonstrou que o primeiro folículo ovulatório, apresentado por éguas em condições tropicais, cresce numa taxa similar ao reportado para éguas que se encontram no hemisfério norte $(2,19$ $\mathrm{mm} \times 2,6 \mathrm{~mm} / \mathrm{dia})^{2}$. Este valor também é muito próximo ao relatado para éguas durante a fase ovulatória no Brasil (2,5 \pm $0,2 \mathrm{~mm} / \mathrm{dia})^{11,12}$. Além disso, o primeiro folículo ovulatório da estação reprodutiva demonstrou ser sensível à aplicação de hCG. Carnevale et al. ${ }^{5}$ também induziram a ovulação em éguas com hCG durante o período transicional e observaram que estas ovularam em média 2,8 dias (1-6 dias) após a administração da gonadotrofina. Neste estudo, o hCG foi administrado quando as éguas apresentaram um folículo $\geq 40 \mathrm{~mm}$ e no mínimo 3 dias de cio. Das 19 éguas, uma $(1 / 19)$ ovulou após 48 horas e, duas (2/19), não ovularam após o tratamento. Os resultados obtidos neste experimento mostram que a administração de hCG foi efetiva mesmo quando utilizado em folículos dominantes $(\geq 35 \mathrm{~mm}$ ) que eventualmente poderiam regredir durante o período transicional, não parecendo ser necessário que o folículo dominante apresente um diâmetro superior a $40 \mathrm{~mm}$, desde que sejam respeitado os níveis de estradiol evidenciados pelo edema uterino ou pelos sinais de cio.

Do mesmo modo, o hCG também mostrou-se eficiente para a acelerar a maturação do oócito, durante o período transicional, indicada pelo número de embriões recuperados por coleta. $O$ índice de recuperação $(69,23 \%)$ obtido neste trabalho apresenta-se similar ao de vários autores que realizaram a coleta durante a estação reprodutiva, embora exista grande variabilidade na literatura $9,13,14,15,16,17,18,19,20$. Assim, a viabilidade do oócito do primeiro folículo ovulatório parece ser igual àquela de outros ciclos durante a estação ovulatória. Todos os embriões coletados mostraram-se viáveis após avaliação visual e após o exame de fluorescência, exaltando a eficiência reprodutiva que pode ser alcançada com o primeiro ciclo. Além disso, as características ultra-estruturais observadas nos embriões coletados são semelhantes àquelas observadas em embriões eqüinos obtidos durante a estação de monta ${ }^{21,22}$. Este dado corrobora para a afirmação de que os embriões obtidos no primeiro ciclo ovulatório da estação são normais e viáveis.

Os resultados obtidos neste trabalho, com relação a qualidade dos embriões obtidos de éguas doadoras no primeiro ciclo da estação reprodutiva não devem ser transpostos para a qualidade do primeiro ciclo de éguas receptoras. Squires, Iuliano e Shideler ${ }^{19}$ e Iuliano e Squires ${ }^{23}$ reportaram que as taxas de prenhez são maiores quando são utilizados ciclos do meio da estação, enquanto Carnevale et al..$^{24}$ obtiveram maiores taxas de gestação quando utilizaram a primeira ovulação das receptoras, mostrando que a temática ainda é motivo de conflito.

A concentração de progesterona, referente ao dia da coleta de embrião, demonstrou que o primeiro corpo lúteo da estação é esteroidogenicamente eficiente, e os valores estão de acordo com vários autores que registraram níveis plasmáticos de progesterona entre 4,0 e 12,0 $\mathrm{ng} / \mathrm{ml}$ para éguas em diestro ${ }^{25,26,27,28}$. Este valor $(7,39 \pm 2,11 \mathrm{ng} / \mathrm{ml})$, entretanto, parece superior ao relatado por Carnevale et al..$^{5}$ que também induziram a primeira ovulação do ano com hCG $(4,9 \mathrm{ng} / \mathrm{ml})$ e ao observado, no $7^{\circ}$ dia após a ovulação, por Arruda et al. ${ }^{29}$ durante a estação reprodutiva $(4,37 \pm 0,21 \mathrm{ng} / \mathrm{ml})$. Desta forma, a indução da ovulação durante o período transicional não parece afetar a formação ou a função do corpo lúteo. Apesar dos valores similares, outros trabalhos concordam que existe uma influência da estação sobre a concentração circulante de progesterona, ocorrendo um progressivo declínio na progesterona plasmática do diestro no período anovulatório ${ }^{30,31}$.

O intervalo médio necessário para a segunda ovulação após a administração da $\mathrm{PGF}_{2} \alpha(10,92 \pm 3,50$ dias $)$ foi similar ao 


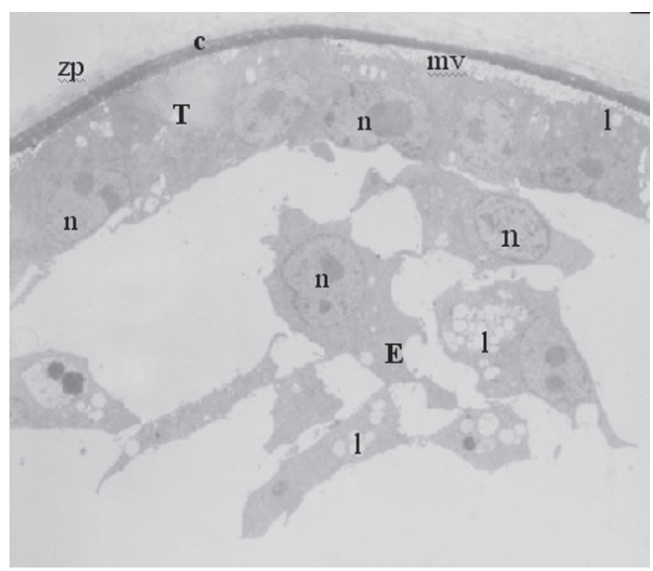

$3 a(2.450 X)$

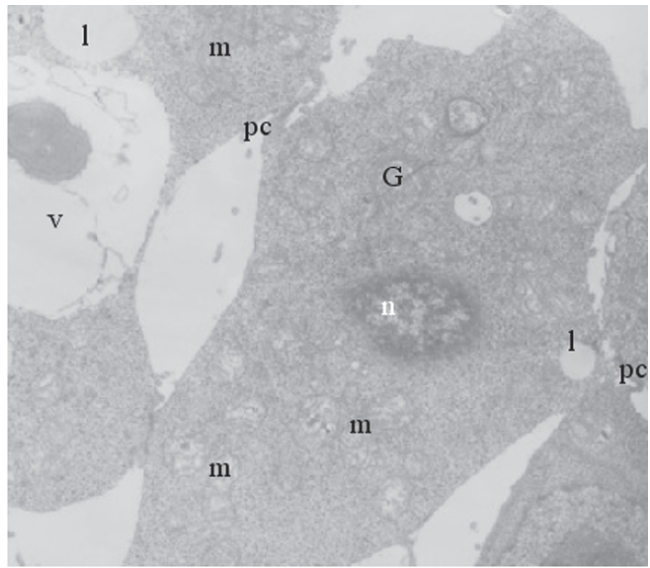

$3 c(13.250 X)$

$\mathrm{T}=$ células do trofoblasto; $\mathrm{E}=$ células do embrioblasto; $\mathrm{G}=$ comlexo de Golgi; $\mathrm{n}$ = núcleo; $\mathrm{nu}=$ nucléolo; $\mathrm{I}$ = gotas de lipídeo; $\mathrm{m}$ = mitocôndria; $\mathrm{mv}=$ microvilosidades; $\mathrm{c}=$ cápsula; $\mathrm{zp}=$ zona pelúcida; $\mathrm{v}=$ vacúolo; $\mathrm{vc}=$ vesícula aberta; $\mathrm{epv}=$ espaço perivitelínico; $\mathrm{cj}=$ complexos juncionais

Figura 3 - Aspecto geral da ultra-estrutura de embriões obtidos de éguas em transição de primavera

relatado durante a estação reprodutiva $(9$ a 10 dias $)^{32,33}$, entretanto, houve um menor grau de sincronia em relação a outros tratamentos que associaram a $\mathrm{PGF}_{2} \alpha$ e hCG ${ }^{34,35}$.

\section{Conclusão}

Os resultados demonstram que, dentro das condições do presente experimento, o primeiro folículo ovulatório do ano produz óvulos viáveis, podendo ser utilizado para a recuperação de embriões com uma boa qualidade. Podemos concluir

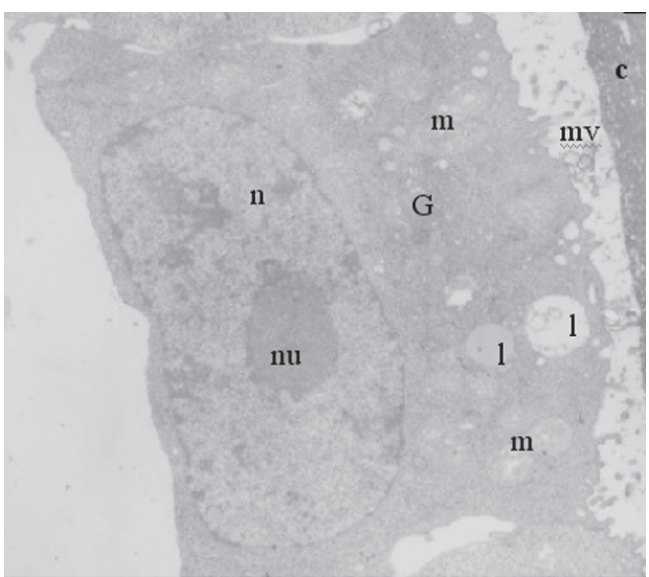

$3 b(13.250 X)$

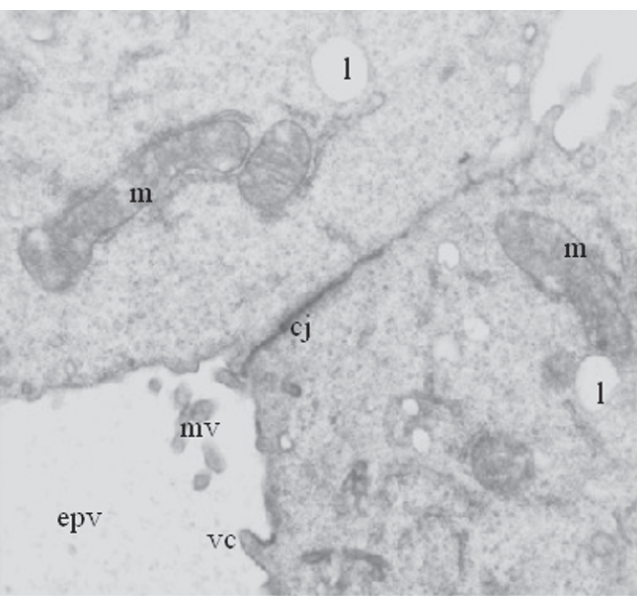

$3 d(23.000 x)$ também que o corpo lúteo formado após a primeira ovulação do ano é funcional e competente, produzindo concentrações de progesterona similares aos corpos lúteos da estação ovulatória e sendo responsivo a aplicação de prostaglandina $\mathrm{F}_{2} \alpha$

\section{Agradecimentos}

Laboratório CALIER do Brasil Ltda, São Paulo, pela doação do Vetecor ${ }^{\circledR}$.

Prof. Frederico Ozanam Papa.

Prof. Eunice Oba. 


\section{Utilization of the first ovulatory cycle of seasonal breeding for embryo production in mares in tropical conditions}

\section{Abstract}

The efficacy of the first ovulation of the breeding season was determined through the response of first pre-ovulatory follicle of the breeding season to hCG, embryo recovery rate, viability of recovered embryos, serum concentrations of progesterone, and response of first $\mathrm{CL}$ to $\mathrm{PGF} \alpha$. Thirteenth mares that were in vernal transition were accompanied until the first pre-ovulatory follicle was detected. At this moment, the ovulation was induced with 2,500 IU hCG (IV) and the mares were inseminated every other day until ovulation. Seven days after the ovulation, embryo recovery was performed and the progesterone concentration was determined. After detection of the first pre-ovulatory follicle of breeding season with $\geq$ $25 \mathrm{~mm}$, it took $14.92 \pm 10.80$ days for the follicle to reach the preovulatory size and $18.00 \pm 11.08$ days to ovulation. After administration of hCG, 11/13 mares ovulated in 48 hours. These follicles growth $2.19 \pm 0.86 \mathrm{~mm} /$ day on average. Nine of 13 mares $(69.2 \%)$ produced embryos and all were considered viable after morfological evaluation and fluorescence exams. The CL appeared competent producing $7.39 \pm 2.11 \mathrm{ng} / \mathrm{ml} \mathrm{P}_{4}$ on average, and responding to $\mathrm{PGF}_{2} \alpha$. According to these results the first ovulatory cycle of the year can be utilized to produce viable embryos.

\section{Referências}

1 DONADEU, F. X.; GINTHER, O. J. Follicular waves and circulating concentrations of gonadotrophins, inhibin and oestradiol during the anovulatory season in mares. Reproduction, v. 124, n. 6, p. 875-885, 2002.

2 GINTHER, O. J. Folliculogenesis during the transitional period and early ovulatory season in mares. Journal Reproduction Fertility, v. 90, p. 311-320, 1990

3 HINES, K. K.; AFFLECK, K. J.; BARROWS, S.P.; MURDOCH, W. L.; FITZGERALD, B. P.; LOY, R. G. Folliclestimulating hormone pulse amplitude decreases with onset of the breeding season in the mare. Biology Reproduction, v. 44, p. 516-521, 1991.

4 SHARP, D. C.; GINTHER, O. J. Stimulation of follicular activity and estrous behavior in anestrous mares with light and temperature. Journal Animal Science, v. 41, p. 1368-1372, 1975.

5 CARNEVALE, E. M.; et al. Effect of human chorionic gonadotropin on time to ovulation and luteal function in transitional mares.
Journal of Equine Veterinary Science, v. 9, p. 27-29, 1989.

6 COLBERN, G.T.; SQUIRES, E. L.; VOSS, J. L. Use of altrenogest and human chorionic gonadotropin to induce normal ovarian cyclicity in transitional mares. Journal Equine Veterinary Science, v. 7, p. 69-72, 1987.

7 GINTHER, O. J. Reproductive biology of the mare: Basic and Applied Aspects. 2.ed. Wisconsin: Equiservices, Cross Plains, 1992. 640 p.

8 VOSS, J. L.; PICKETT, B. W.; BURWASH, L. D.; DANIELS W. H. Effect of human chorionic gonadotropin on duration of estrous cycle and fertility of normally cycling, nonlactating mares. Journal American Veterinary Medical Association, v. 165, p. 704-706, 1974.

9 ALVARENGA, M. A.; LANDIM-ALVARENGA, F.C;MEIRA, $C$. Some modifications in the technique used to recovery equine embryos. Equine Veterinary Journal, v. 15, p. 111-112, 1993

10 McKINNON, A. O.; SQUIRES, E. L. Equine embryo transfer. Veterinary Clinical North American: Equine Practice, v. 4, p. 305-33, 1988.

11 GODOI, D. B.; GASTAL, E. L.; GASTAL, M. O. A 
comparative study of follicular dynamics between lactating and non-lactating mares: effect of the body condition. Theriogenology, v. 58, p. 553-556, 2002.

12 MACHADO, M. S.; ARANTES, M.; PERES, K. R; LEÃO, K. M.; CARMO, M. T.; SQUIRES, E. L.; ALVARENGA, M. A. Dinâmica folicular, número de ovulações e embriões recuperados em éguas submetidas a tratamento superovulatório, utilizando-se extrato de pituitária eqüina e FSH eqüino purificado. Revista Brasileira de Reprodução Animal, v. 27, n. 3, p. 506508, 2003.

13 GRIFFIN, J. L.; CASTLEBERRY, R. S.; SCHNEIDER Jr., H. S. Influence of day of collection on recovery rate in mature cycling mares. Theriogenology, v. 15. p. 106, 1981

14 HINRICHS, K. A simple technique that may improve the rate of embryo recovery on uterine flushing in mares. Theriogenology, v. 33, p. 937-942, 1990.

15 JILL BOWEN, M.; SALSBURY, J. M.; BOWEN, J. M.; KRAMER, D. C. Non-surgical embryo auto-transfer in the mare. Equine Veterinary Journal, v. 3, p. 100102, 1985. Supplement.

16 MEIRA, C.; ALVARENGA, M. A.; HENRY, M. FERREIRA, J. C. P. Transferência não cirúrgica de embriões eqüinos: Estudo retrospectivo. ARS Veterinária, v. 9, n. 2, p. 169, 1993.

17 SQUIRES, E. L.; IMEL, K. J.; IULIANO, M. F.; SHIDELER, R. K. Factors affecting reproductive efficiency in an equine embryo transfer programe. Journal Reproduction Fertility, v. 32, p. 409-414, 1982a. Supplement.

18 SQUIRES, E. L.; IMEL, K. J.; SHIDELER, R. K.; VOSS, J. L. Recent advances in equine embryo transfer. Proccedings American Association Equine Practice, v. 26, p. 161-172, 1980.

19 SQUIRES, E. L.; IULIANO, M. F.; SHIDELER, R. K. Factors affecting the success of surgical and non surgical equine embryo transfer. Theriogenology, v. 17, p. 3541,1982 b

20 TISCHNER, M. Embryo recovery from polish pony mares and preliminary observations on foal size after transfer of embryos to large mares. Equine Veterinary Journal, p. 96-98, 1985. Supplement 3.

21 LANDIM-ALVARENGA, F. C.; ALVARENGA, M A.; MEIRA, C. Transmission electron microscopy of equine embryos cryopreserved by different methods. Equine Veterinary Journal, v. 15, p. 67-70, 1993. Supplement.
22 WILSON J. M.; CACECI T.; POTTER G. D. KRAEMER D. C. Ultrastructure of cryopreserved horse embryos. Journal of Reproduction Fertility, v. 35, p. 405-17, 1987. Supplement.

23 IULIANO, M. F.; SQUIRES, E. L. Effect of age of equine embryos and method of transfer on pregnancy rate. Journal Animal Science, v. 60, p. 258-263, 1985.

24 CARNEVALE, E. M.; et al Factors affecting pregnancy rates and early embryonic death after equine embryo transfer. Theriogenology, v. 54, p. 965-979, 2000.

25ALLEN, W. A.; HADLEY, J. C. Blood progesterone concentrations in pregnant and non-pregnant mares. Equine Veterinary Journal, v. 6, n. 2, p. 87-93, 1974.

26 LOPATE, C.; THERELFALL, W. R. Assessment of luteal function with progesterone enzime immunoassays in the horse mare. Theriogenology, v. 35, n. 3, p. 583590, 1991.

27 ROMANO, M. A. Níveis de progesterona no ciclo estral, duração de estro, intervalo entre partos e momento de ovulação em eqüinos árabes. 1993. 93 f. Dissertação (Mestrado) - Faculdade de Medicina Veterinária e Zootecnia, Universidade de São Paulo, São Paulo, 1993.

28 SMITH, I. D.; BASSETT, J. M.; WILLIANS, T. Progesterone concentrations in the peripheral plasma of the mare during the oestrus cycle, Journal of Endocrinology, v. 47, n. 4, p. 523-524, 1970.

29 ARRUDA, R. P.; et al Existem relações entre tamanho e morfoecogenicidade do corpo lúteo detectados pelo ultra-som e os teores de progesterona plasmática em receptoras de embriões eqüinos? Brazilian Journal of Veterinary Research and Animal Science, v. 38, p. 233239, 2001.

30 KING, S. S.; NEQUIN, L. G.; DRAKE, S.; HEBNER, T. S.; ROSER, J. F.; EVANS, J. W. Progesterone levels correlate with impeding anoestrus in the mare. Journal Equine Veterinary Science, v. 8, p. 109-111, 1988.

31 NAGY, P.; HUSZENICZA, G.; REICZIGEL, J.; JUHÁSZ, J.; KULCSÁR, M.; ABAVÁRY, K.; GUILLAUME, D. Factors affecting plasma progesterone concentration and the retrospective determination of time of ovulation in cyclic mares. Theriogenology, v. 61 , p. 203-214, 2004

32 IMEL. K. J.; SQUIRES, E. L.; ELSDEN, R. P.; SHIDELER, R. K. Collection and transfer of equine embryos. Journal American Veterinary Medical Association, v. 179, p. 987-991, 1981.

33 SQUIRES, E. L.; COOK, V. M.; VOSS, J. L. Collection 
and transfer of equine embryos. Bulletin Animal Reproduction Laboratory, v. 1, p. 1-37, 1985.

34 HYLAND, J. H.; BRISTOL, F. Sinchronization of oestrus and timed insemination of mares. Journal Reproduction Fertility, v. 27, p. 251-255, 1979. Supplement.

35 PALMER, E.; JOUSSET, B. Synchronization of oestrus in mares with a prostaglandin analogue and hCG. Journal Reproduction Fertility, v. 23 , p. 269-274, 1975. Supplement. 